сформировать личность, ее убеждения, ценности, мировоззрение, формируется только в процессе социализации. В свое время выдающийся советский психолог Лев Семенович Выготский охарактеризовал личность как социализированного индивида, самостоятельную целостную психическую систему, которая выполняет определенные функции, основными из которых являются - творческое освоение общественного опыта и включение человека в систему общественных отношений. Все стороны личности обнаруживаются только в деятельности и в отношениях с другими людьми. Личность существует, проявляется и формируется в деятельности и общении, под непосредственным... влиянием ближайшего окружения, микросреды...

Значительная роль в организации такой уникальной микросреды принадлежит образованию - важнейшему институту социализации, как раз и обеспечивающему условия для сочетания знаний с эмоциональными, «живыми» межличностными отношениями, формированию особой когнитивной способности - социального интеллекта, необходимого для эффективного межличностного взаимодействия и успешной социальной адаптации. Современному сложному, постоянно развивающемуся обществу нужна именно такая самостоятельная личность, потому что несамостоятельный, интеллектуально и социально неразвитый человек не в состоянии правильно понять и оценить стремительные социальные изменения, боится их, и в результате вступает в конфликт и с самим собой, и с социумом. В такой ситуации становится возможным манипулирование сознанием несамостоятельной личности, ее выбором социальных ролей и моделей поведения с помощью лживой информации и деструктивного общения со стороны всевозможных псевдоагентов социализации в лице доморощенных недалеких блогеров и им подобных.

Таким образом, дистанционное образование, утвердив свою значимость в экстремальных условиях пандемии, обрело право на существование лишь как дополнение к основному, проводящемуся очно и в режиме реального времени. Опыт пандемии оказался очень важным в процессе развития различных альтернативных методик обучения и доказал - при всем развитии технического прогресса необходимость традиционных методов и форм образования, основой которого является прямое « живое» взаимодействие преподавателя и студентов.

$$
\text { *** }
$$

1. Выготский Л. С. Мышление и речь. М.-Л.: Соцэкгиз, 1934.

2. Мудрик, А. В. Социальная педагогика .учеб. для студ. пед. вузов / Под ред. В.А. Сластенина. - 3-е изд., испр. и доп. - М.: Академия, 2000.

3. Швандерова А.Р. Инновации в системе образования - новое или незабытое старое? // Материалы международной научно практической конференции «Современное состояние и приоритетные напрвления развития аграрной экономики и образования». ДОНГАУ, 7 февраля 2019 (РИНЦ).

\title{
Шоидарвозова Г.С. \\ Инновационные подходы в образовательном процессе на примере Хорогского государственного университета
}

Хорогский государственный университет имени М. Назаршоева

doi: $10.18411 /$ sr-10-04-2021-64

(Таджикистан, Хорог)

\section{Аннотация}

Мировая тенденция сложилась таким образом, что основная роль отводиться электронным ресурсам. Поэтому в данной статье рассматривается проблемы внедрения электронно-образовательных ресурсов в учебный процесс на примере Хорогского государственного университета. Кроме того ведущая роль в статье отводиться педагогу, как основного субъекта для реализации программы внедрения 
информационно-коммуникационных технологий в вузах. В статье также рассмотрены ряд проблем при внедрении новых информационных технологий с которым столкнулся Хорогский государственный университет (ХоГУ). Показаны необходимость внедрения информационно - коммуникационных технологий в деятельности Хорогского государственного университета на примере международных проектов. Выявлены барьеры препятсвующие внедрению информационно - коммуникационных технологий в образовательный процесс.

Ключевые слова: информационные технологии, учебный процесс, режиме online, инновация, инновационные технологии, инновационная деятельность, ХоГУ, ППС, ACY.

\section{Abstract}

The global trend has developed in such a way that the main role is assigned to electronic resources. Therefore, this article discusses the problems of introducing electronic educational resources into the educational process on the example of Khorog State University. In addition, the leading role in the article is assigned to the teacher, as the main subject for the implementation of the program for the introduction of information and communication technologies in universities. The article also discusses a number of problems in the implementation of new information technologies that the Khorog State University (KhoSU) faced. The necessity of introducing information and communication technologies in the activities of Khorog State University is shown on the example of international projects. Identified barriers to the introduction of information and communication technologies in the educational process.

Keywords: innovation, innovative activity, tradition, institution, teacher.

В век информатизации владение педагогами вузов информационными технологиями становится необходимостью. Задача педагога состоит в том, чтобы помогать каждому стать более знающим и находчивым, эффективно управлять своей жизненной траекторией, наслаждаться полноценной и насыщенной жизнью, растить профессионалов, которые умеют использовать ИКТ для работы с информацией, способствующей решению проблем и производству новых знаний. Педагогическая технология - организация процесса обучения для получения и преобразования информации.

Следует отметить, что система образования Таджикистана находится в стадии динамичного обновления, импульсом которому послужило процессы ее реформирования. Инновационные технологии охватывают все компоненты учебно воспитательного процесса сферы образования. Использование современных информационных технологий в деятельности педагога - одна из актуальнейших педагогических проблем в учебном процессе ВУЗ-а. Эффективность решения данных проблем во многом обеспечивается внедрением в учебный процесс вузов инновационных технологий, активных методов обучения.

Рассмотрение этой проблемы невозможно без понимания основных терминов, таких как «инновация», «инновационная деятельность», и их соотношения с такими понятиями, как «новшество», «нововведение».

Инновация (innovatis: in - в, novus - новый) в латинском языке означает вхождение нового в некоторую сферу, вживление в нее и порождение целого ряда изменений в этой сфере. Значит, инновация - это, с одной стороны, процесс обновления, реализации, внедрения, а с другой - это деятельность по увеличению инноваций в определенную практику [4]. 
Инновационная деятельность является одним из аспектов работы современного вуза в режиме развития, и представляет собой последовательность определенных стадий, характеризующихся позитивными качественными изменениями.

Инновационная деятельность подразумевает своеобразные отклонения от норм, признанных в конкретных социально-экономических условиях стандартов; введение и заимствование альтернативных норм и т.д. Она предполагает сознательное преобразование действительности для обеспечения совокупности сил и средств для дальнейшего развития [2, 47].

Новый подход к инновационным процессам был связан с противопоставлением инновации и институционализации. В этот период под инновацией понимали такую форму индивидуального или группового поведения, когда отдельный человек или группа достигают социально признанной цели средствами, которые еще не были институализированы в предшествующем обществе. Инновация оказывается связанной с процессами институциализации новых форм поведения [5].

Эффективное достижение цели и задач подготовки будущего специалиста к инновационной деятельности на практике имеет свою специфику в каждом отдельно взятом учебном заведении и требует тщательно продуманной и слаженной работы всех субъектов образовательного процесса вуза. Хорогский государственный университет (ХоГУ) одним из первых начал внедрять новую технологию в процессе обучения. При внедрении новых информационных технологий университет столкнулась с рядом нерешенных проблем, к которым относятся:

- неподготовленность преподавателей к новым инновационным технологиям. Одной из основных проблем при реализации программы внедрения инновационных технологий является невысокий уровень цифровых компетенций у профессорско - преподавательского состава (ППС), а также отсутствующие у них навыков самоорганизации, что требует дополнительного обучения. Еще одной проблемой оказалось то, что 35\% ППС старше 60 лет (и треть - в возрасте от 45 до 59 лет) вообще не умеют пользоваться интернетом и дистанционными образовательными сервисами. Такую цифровую неготовность демонстрировал каждый пятый преподаватель в вузе.

Следует отметить, что те преподаватели, которые обладали цифровой грамотностью, во время введенной инновации не всегда могли полноценно проводить занятия: пытаясь вести дистанционные занятия из рабочего кабинета, они столкнулись со скоростным барьером интернета.

- неподготовленность самых студентов. Во время перехода к новым технологиям студенты не были морально готовы к такому процессу. К примеру, студенты привыкли к традиционным экзаменам, т.е. с одной стороны студент, а с другой преподаватель. В ХоГУ обучаются студенты не только из города Хорога, но из сельской местности. Однако, по нашим подсчетам более $60 \%$ это студенты из сельской местности, где ситуация более критическая. Доход семьей, проживающих в сельской местности намного ниже, чем в городе, и поэтому у студентов возникают проблемы с выполнением домашней работы поскольку не у всех имелись ноутбуки в семье.

нехватка ресурсов. Очевидно, что качество внедрения инновационных технологий в ХоГУ на сегодняшний день определяется не столько уровнем подготовки ППС, сколько технологическими и техническими факторами. Однако для перехода на инновационное обучение в вузе были проблемы не только вышеназванные факторы, но и нехватка материальных ресурсов в самом вузе. Например, нехватка компьютеров, электронных досок, отсутствие интернета, нехватка аудиторий и т.д.

Несмотря на все эти трудности ХоГУ сделал первый шаг на пути к инновациям путём внедрения инновационных технологий, модернизиции содержания преподаваемых дисциплин, внедрения в образовательный процесс результаты научноисследовательских работ. 
Хотелось бы отметить, что роль международных проектов в инновационном развитии Хорогского государственного университета имени М. Назаршоева огромна. Для реализации стратегических направлений в области внедрения инноваций в систему высшего профессионального образования руководство Хорогского госуниверситета тесно сотрудничает с международными проектами, такими как ERASMUS+, MEDIATE, QUADRIGA, TACES, qSMART, MIND, HiedTech. Особо хотелось бы остановиться на проекте ERASMUS+, HiedTech. Благодаря данному проекту 5 преподавателей прошли курс переподготовки, 100 преподаватели обучались он-лайн курсам. При содействии этого проекта в ХоГУ были открыты 4 новых лабораторий с новейшим оборудованием. Наши исследование показало, что после прохождения подготовки по проекту ERASMUS+, HiedTech ППС стали активно внедрять в учебный процесс новые знания по использованию инновационных технологий, использовать интерактивные методы и элементы обучения, что позволяет успешно решать целый спектр задач подготовки будущих специалистов в вузе.

Как известно, этот год (2020) был самым сложным, поскольку пандемия повлияла на все сферы нашей жизни. Несмотря на это ППС ХоГУ в этот период активно участвовали в он-лайн курсах по повышению квалификации. Все эти факторы положительно влияют на качество образования в вузе. В результате комплексных мер повышается успеваемость студентов, у них формируется достаточная база для применения инноваций в педагогической деятельности, они выходят на творческий уровень овладения профессией. Кроме того участвуют в конференциях межвузовского и республиканского уровня.

В университете широко используется диагностический метод мониторинга качества образования. Данные диагностики используются для дальнейшей корректировки учебной деятельности. Успешно функционирует автоматизированная система компьютерного тестирования. Данная система работает по http - протоколу передачи гипертекста, что позволяет проводить тестирование не только по локальной сети, а также и через сеть Internet, и это является основой системы дистанционного обучения. Система обеспечивает полную интеграцию в информационную систему и использование данных, полученных на тестировании, для автоматизированного расчета итоговых оценок. В Хорогском госуниверситете создана обширная база тестовых заданий по дисциплинам.

В ХоГУ эффективно функционирует информационно - образовательная сеть университета. Логическая структура информационной системы университета включает следующие элементы:

— web-сайт ХГУ (www.khogu.tj);

- дистанционную образовательную систему (www.fosilavikhogu.tj);

- автоматизированную информационную систему управления учебным процессом.

— В учебный процесс внедрена автоматизированная система управления (АСУ) вуз с подсистемами:

- “Деканат” (контингент, текущая и итоговая успеваемость, рейтинг, транскрипт);

— “Учебный отдел” (расчет часов, контингент - студенты, расписание, сессия);

- “Дистанционное обучение".

Ежегодно АСУ вуза пополняется новыми подсистемами.

Таким образом, можно сказать, что внедрение в систему обучения инновационных технологий и новых методов позволяют повысить эффективность обучения, и приводит к новой модели высшего образования, его реструктуризации. Но для более полного внедрения инновационных технологий в систему обучения в ХоГУ 
ведущую роль играет разработка стратегического плана по внедрению эффективной действующей модели инновационного образования и полноценное развитие профессионализма и личностных качеств будущих специалистов. В этой связи основное усилие учебно - методического управления вуза необходимо направить на системное внедрение новых образовательных технологий обучения и приданию учебному процессу инновационности и креативности.

1. Владимиров А.И. Об инновационной деятельности вуза / А.И. Владимиров. - М.: ООО «Издательский дом Недра», 2012. - 72 с.

2. Денякина Л.М. Инновационные технологии в управлении образовательным учреждением: дис. канд. пед. наук. - Якутск: ЯГУ, 2001. - 163 с.

3. Куликова О.В.Особенности инновационной модели высшего образования [Электронный ресурс]/ О. В. Куликова, И. А. Гулей // Современные проблемы науки и образования. - 2014. - № 6. - URL: http://cyberleninka.ru/article/n/osobennosti-innovatsionnoy-modeli-vysshego-obrazovaniya (дата обращения: 01.12.2016)

4. Новейший философский словарь: 2-е изд., переработ. и дополн. - Минск : Интерпрессервис ; Книжный дом, 2001. - 1280 с.

5. Слободчиков, В. И. Инновации в образовании: основания и смысл / В. И. Слободчиков. [Электронный ресурс]. dom.ru/index.php?action=article\&id=2 (26.10.2006).

\section{Borsukov A.V.', Krukovskiy S.B. ${ }^{2}$, Markelova L.N. ${ }^{2}$,Gorbatenko O.A. ${ }^{1}$, Venidiktova D.Yu. ${ }^{2}$}

Contrast-enhanced ultrasound of kidneys in patients with type 2 diabetes and chronic pyelonephritis: a new dosage of the contrast-enhanced agent

${ }^{1}$ Smolensk State Medical University, the Ministry of Health of the Russian Federation ${ }^{2}$ Regional States Budgetary Healthcare Institution "Clinical Hospital No. 1"

(Russia, Smolensk)

doi: $10.18411 /$ sr-10-04-2021-65

\section{Abstract}

Objective. To evaluate the diagnostic efficacy of the contrast-enhanced ultrasound examination of kidneys in patients with chronic pyelonephritis with a dose of injected contrast agent $-1.0 \mathrm{ml}$.

Materials and methods. In 2020, 20 patients with chronic pyelonephritis were examined on the basis of the Fundamental research laboratory "Diagnostic Researches and Minimally Invasive Technologies", Smolensk State Medical University. All patients underwent ultrasound examination Doppler mapping mode of the kidneys and the. Also, all patients underwent contrast-enhanced ultrasound examination of the kidneys for the diagnosis of angionephrosclerosis.

Results. Using the improved technique in patients of group 2 compared with patients in group 1, the quality of the images obtained was preserved. In patients of group 1 with chronic pyelonephritis, the quantitative indicators correspond to the initial manifestations of angionephrosclerosis.

Conclusion. Thus, the improved CEUS technique with the use of $1.0 \mathrm{ml}$ of contrast agent showed good possibilities in the diagnosis of angionephrosclerosis in patients with chronic pyelonephritis.

Key words: contrast-enhanced ultrasound, angionephrosclerosis, non-alcoholic fatty liver disease

Introduction: According to modern data, over the past decade, the number of people with type 2 diabetes mellitus (DM) has doubled [1]. The amount of funds spent on diabetes treatment by the end of 2019 amounted about $\$ 760$ billion [1, 2]. Globally, the number of 